\title{
An Empirical Study on Cloud Accounting Awareness and Adoption among Accounting Practitioners in Sri Lanka
}

\author{
S.H.M.L Walakumbura* \\ DOI: 10.29322/IJSRP.11.07.2021.p11543 \\ http://dx.doi.org/10.29322/IJSRP.11.07.2021.p11543
}

\begin{abstract}
Willingness towards adoption and non adoption of cloud computing can be highlighted as a controversial aspect even in the current scenario. Hence this study has been developed by the researcher to find out the cloud accounting awareness and adoption among accounting practitioners in Sri Lanka. The primary data has been collected from 149 accounting practitioners in the private sector in Sri Lanka. Reasons for adoption and non adoption have been considered as the outlying independent factors. Frequency analysis and Factor analysis has been used for the analysis purpose and the findings of the study highlights easy geographical access, unlimited data storage, processing capacity and automatic backup, standardized interfaces for the preparation of accounting reports and facilitates generation of accounting reports whenever needed as the main reasons for the adoption by accounting practitioners. Not popular among peer groups, lower confidentiality of data and lack of trust in internet based services are highlighted as the main reasons for the non adoption of the cloud accounting. The findings of the study can be pave the way to fulfill the gap in existing literature in the developing economies like Sri Lanka and these finding will be useful for academics, policy makers, accounting practitioners and cloud accounting developers.
\end{abstract}

Index Terms- Cloud accounting, Cloud computing, Financial health

\section{INTRODUCTION}

Financial accounting paves the way to track the business operations and also it helps to provide a snapshot of the financial health of the organization. Variety of statements such as statement of financial position, statement of profit and loss and statement of cash flows will be made in order to provide financial information for the stake holders and all other related parties in order to empower their decision making. Step by step financial accounting also has reached to an era of information technology and accounting practitioners are willing to use these emerging technologies in order to perform their tasks efficiently and effectively.

Dimitriu and Matei (2015) have defined cloud accounting as software or else an accounting application where the actions are performed on servers while offering online services for the application users. Though cloud accounting seems to be fairly new to many people, this concept runs back to 1990's. In cloud accounting, all the data will be delivered to a central hub and will process and saved in the cloud while giving the access to any person from any geographical location.

As per Mell \& Grance ( 2011), software as a service (Saas), Infra structure as a service ( Iaas), Platform as a service (Paas) and Business process as a service (Bpaas) are considered as the most commonly used cloud accounting services. QuickBook Online, FreshBooks, Xero, Wave, Zoho Books, Oracle, Netsuite, Kashoo, GoDaddy Online Book keeping, Sage Business Cloud, Zip Books can be demarcated as the best cloud accounting software platforms ( Honea, 2021).

By applying this latest technology, firms may gain benefits such as easy accessibility, less cost on computer components and less labor requirement, more accurate and precise reports, improved communication and etc. Even though there are so many reasons to shift from traditional accounting to cloud accounting, a huge delay in shifting can be noticed due to the fact of lack of awareness by potential users and the professional practitioners.

Therefore this study attempts to find out the awareness and adoption barriers of cloud accounting among accounting practitioners in Sri Lanka and will pave the way towards enriching existing literature of cloud accounting in developing countries.

\section{A) Problem statement}

The problem statement of this research paper can be demarcated as,

"What is the awareness level of clouding accounting and its adoption among the accounting practitioners in Sri Lanka and what are the reasons for adoption and non adoption among them?"

B) Objectives

Referring to the problem statement stated above, following research questions could be derived pertaining to cloud accounting awareness and adoption in Sri Lankan context.

1)To identify the level of awareness and adoption of cloud based accounting among accounting practitioners in Sri Lanka. 
2) To find out the reasons for adoption and non adoption of cloud accounting among accounting practitioners in Sri Lanka.

3) To increase the awareness of cloud accounting among accounting practitioners in Sri Lanka.

\section{C) Significance of the study}

The findings of the study will help to enrich the existing literature on cloud accounting in the context of developing and emerging economies. As well these insightful findings will be helpful for accounting practitioners to enhance their knowledge in these aspects and cloud accounting developers to up come with relevant changes to match with the requirements of the accounting practitioners.

\section{d) Literature review}

A key definition for cloud accounting has not been finalized yet but several researchers and organizations have derived with definitions as follows. "Cloud accounting or online accounting" acts like accounting applications installed on users' computers, but it is performed on servers offering online services and uses can access them through web browsers" (Dimitriu \& Matei 2015, p.2). Mihalache (2011) defines cloud accounting as 'a modern concept in computer processing of accounting data based on the concept of cloud computing, which represents a set of distributed computing services, applications, access to information and data storage without the user having to know the physical location and configuration of systems providing these services' (cited in Bosoteanu, 2016).

A research has been carried out in Bangalore city by using 30 chartered accountants and 30 post graduate accounting teachers and have found that $6.67 \%$ of both chartered accountants and post graduate accounting teachers are having awareness while $13.33 \%$ of Chartered accountants and $33.3 \%$ of post graduate teachers does not know about cloud accounting. The empirical findings of the study suggest that there is no significance difference in awareness between the post graduate teachers and chartered accountants in Bangalore.

Dimitriu and Matei ( 2015) conducted study using accounting professionals and found that cloud accounting has been used to empower the professionals by making their work more easy and effective. As well the empirical findings of the study has suggested that cloud accounting has given solution to organizations in relevant to their security, expenses and collaborations.

Ebenezer et.al (2004) has done a study using accounting professionals and accounting students in Ghana and the empirical findings of the study suggest that though accountants possess knowledge about cloud accounting, they do not like to use cloud accounting due to the risk which is involved in cloud accounting soft wares. As financial information considered as confidential, they consider the less security to the data as the major drawback of cloud accounting. As well the researchers have highlighted that cloud accounting has enhanced the timeliness and speed of data and decision making process. As per the existing literature, cloud accounting can be considered as a controversial area for even today.

\section{METHODOLOGY}

The researcher has used a structured questionnaire in order to obtain primary data and the relevant five likert scaled questionnaire was distributed accounting practitioners in the private sector based on convenient sampling method. The questionnaire is composed of two parts. The first part concerned with collecting data about the demographic characteristics of respondents, while the second part donated to collected data about the possible reasons for using cloud based accounting and possible reasons for not using cloud based accounting. 
A) Analysis for level of awareness

\section{DATA ANALYSIS AND PRESENTATION}

FIGURE I: LEVEL OF AWARENESS

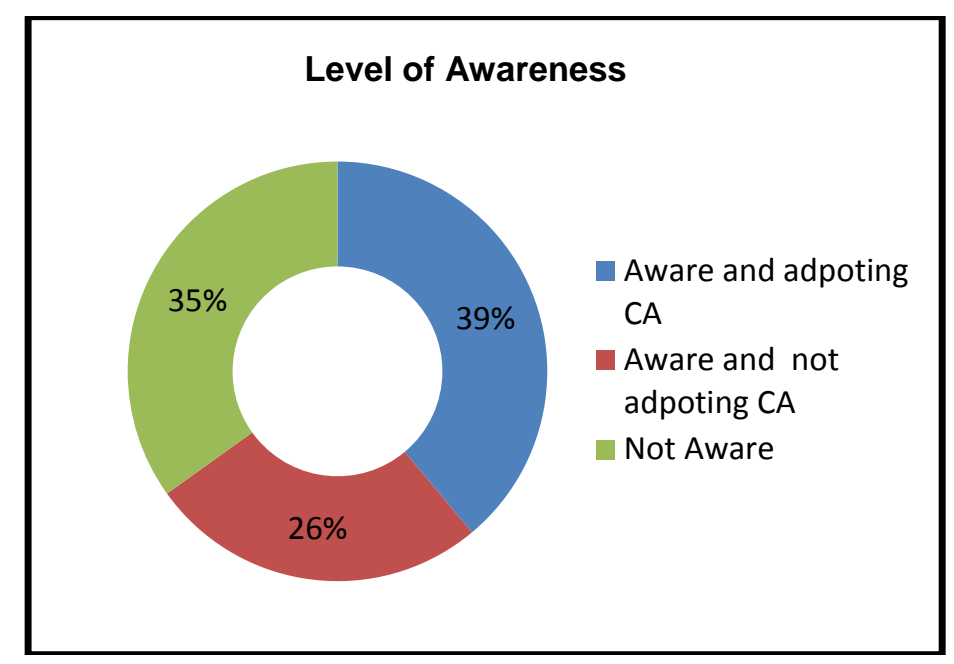

Source: Survey data

According to the figure I, 39\% of the respondents are aware and adopting the cloud accounting in their daily practice while $26 \%$ of the respondents are aware and not adopting cloud accounting in their daily practice. $35 \%$ of the respondents are not aware about the cloud accounting at all.

\section{B) Cronbach's Alfa}

TABLE I : TEST OF RELIABILITY

\begin{tabular}{ll}
\hline Variable & Cronbach's Alpha \\
\hline Adoption of cloud accounting & 0.953 \\
& \\
Non adoption of cloud accounting & 0.886
\end{tabular}

Source: Survey data

Table I shows the results of the reliability test and Cronbach Alpha for each independent variable exceeds 0.7. Hence can derive to the fact that questionnaire can be considered as reliable to proceed with further analysis.

\section{C) Normality test}

TABLE II: TEST OF NORMALITY

\begin{tabular}{lll}
\hline Variable & Skewness & Kurtosis \\
\hline Adoption of cloud accounting & -0.997 & -0.099 \\
Non adoption of cloud accounting & -0.929 & 0.620 \\
\hline
\end{tabular}

Source: Survey data

Table II demonstrates the results of the normality test and also skewness and kurtosis values lies around 0 . Hence we can derive to the fact that data set is normally distributed to proceed with. 


\section{D) Factor analysis}

TABLE III: Factor analysis

\begin{tabular}{|c|c|c|c|c|}
\hline & Indicator & Communalities & Loading & KMO \\
\hline \multirow{11}{*}{$\begin{array}{l}\text { Adoption of } \\
\text { cloud } \\
\text { accounting }\end{array}$} & $\begin{array}{l}\text { Unlimited and easy } \\
\text { geographical access }\end{array}$ & 0.938 & 0.878 & 0.849 \\
\hline & $\begin{array}{l}\text { Less capital expenditure } \\
\text { on software and hardware }\end{array}$ & 0.950 & 0.888 & \\
\hline & $\begin{array}{l}\text { Helps to reduce the labor } \\
\text { requirement for IT staff }\end{array}$ & 0.925 & 0.851 & \\
\hline & Provides Better security & 0.847 & 0.876 & \\
\hline & $\begin{array}{l}\text { Automation will reduce the } \\
\text { number of tasks and task load of an } \\
\text { accountant }\end{array}$ & 0.929 & 0.856 & \\
\hline & $\begin{array}{l}\text { capability to meet complex } \\
\text { demands }\end{array}$ & 0.564 & 0.656 & \\
\hline & $\begin{array}{l}\text { Facilitates generation of } \\
\text { accounting reports whenever needed }\end{array}$ & 0.745 & 0.570 & \\
\hline & $\begin{array}{l}\text { Can gather audit evidences } \\
\text { and possible breaches }\end{array}$ & 0.782 & 0.751 & \\
\hline & $\begin{array}{l}\text { Unlimited data storage, } \\
\text { processing capacity and automatic } \\
\text { backup }\end{array}$ & 0.859 & 0.695 & \\
\hline & $\begin{array}{l}\text { Standardized interfaces for } \\
\text { the preparation of accounting reports }\end{array}$ & 0.926 & 0.699 & \\
\hline & $\begin{array}{l}\text { Promotes improved } \\
\text { communication and collaboration }\end{array}$ & 0.585 & 0.717 & \\
\hline \multirow{6}{*}{$\begin{array}{l}\text { Non adoption } \\
\text { of cloud } \\
\text { accounting }\end{array}$} & $\begin{array}{l}\text { Cloud accounting is not popular among } \\
\text { peer groups }\end{array}$ & 0.822 & 0.618 & 0.788 \\
\hline & $\begin{array}{l}\text { No having access to high } \\
\text { speed internet }\end{array}$ & 0.811 & 0.635 & \\
\hline & $\begin{array}{l}\text { Not knowing what can do with cloud } \\
\text { accounting or cloud computing }\end{array}$ & 0.792 & 0.719 & \\
\hline & $\begin{array}{l}\text { Confidentiality of the data is low and } \\
\text { data might get hacked }\end{array}$ & 0.903 & 0.864 & \\
\hline & $\begin{array}{l}\text { Lack of trust in internet based } \\
\text { services }\end{array}$ & 0.806 & 0.690 & \\
\hline & $\begin{array}{l}\text { future with cloud accounting } \\
\text { is not so visible }\end{array}$ & 0.628 & 0.792 & \\
\hline
\end{tabular}

Source: Survey data

According to the table III, all the communalities are above 0.4 and can derive to the fact that they are measuring underlying factors and no any variable need to be excluded from the model. As well factor loadings have been computed after varimax rotation and all the loadings are above 0.4.Hence can derive to the fact factors which is adopted by the researcher is important. KMO (Kaiser Meyer Olkin) test values of the above table lies above 0.7 can conclude that the sample adequacy lies there in the study.

This publication is licensed under Creative Commons Attribution CC BY. 


\section{E) Frequency analysis for adoption of cloud accounting}

TABLE IV: FREQUENCY ANALYSIS

\begin{tabular}{|c|c|c|c|c|c|}
\hline \multirow{2}{*}{ Indicator } & \multicolumn{5}{|c|}{ Frequency $(\mathrm{n})=58$} \\
\hline & SD & $\mathrm{D}$ & $\mathrm{N}$ & A & SA \\
\hline Unlimited and easy geographical access & 1 & 2 & 0 & 41 & 14 \\
\hline Less capital expenditure on software and hardware & 0 & 9 & 3 & 26 & 20 \\
\hline Helps to reduce the labor requirement for IT staff & 4 & 3 & 0 & 25 & 26 \\
\hline Provides Better security & 7 & 0 & 8 & 30 & 13 \\
\hline Automation will reduce the number of tasks and task load of an accountant & 3 & 7 & 0 & 27 & 21 \\
\hline capability to meet complex demands & 8 & 5 & 15 & 21 & 9 \\
\hline Facilitates generation of accounting reports whenever needed & 1 & 0 & 5 & 31 & 21 \\
\hline Can gather audit evidences and possible breaches & 5 & 0 & 12 & 18 & 23 \\
\hline Unlimited data storage, processing capacity and automatic backup & 8 & 0 & 0 & 36 & 14 \\
\hline Standardized interfaces for the preparation of accounting reports & 6 & 0 & 0 & 28 & 24 \\
\hline Promotes improved communication and collaboration & 0 & 9 & 7 & 22 & 20 \\
\hline
\end{tabular}

Source: Survey data

*Special note: $\mathrm{SD}=$ Strongly disagree, $\mathrm{D}=$ Disagree, $\mathrm{N}=\mathrm{Neutral}, \mathrm{A}=$ Agree and $\mathrm{SA}=$ Strongly agree

According to the table IV, unlimited and easy geographical access, unlimited data storage, processing capacity and automatic backup, Standardized interfaces for the preparation of accounting reports and Facilitates generation of accounting reports whenever needed has shown the higher frequencies. Hence those can be considered as the main reasons for the adoption of cloud accounting among the accounting practitioners.

\section{F) Frequency analysis for non adoption of cloud accounting}

TABLE V: FREQUENCY ANALYSIS

\begin{tabular}{|c|c|c|c|c|c|}
\hline \multirow{2}{*}{ Indicator } & \multicolumn{5}{|c|}{ Frequency $(n)=39$} \\
\hline & SD & $\mathrm{D}$ & $\mathrm{N}$ & A & SA \\
\hline Cloud accounting is not popular among peer groups & 1 & 5 & 3 & 6 & 24 \\
\hline No having access to high speed internet & 3 & 4 & 14 & 16 & 2 \\
\hline Not knowing what can do with cloud accounting or cloud computing & 25 & 6 & 0 & 6 & 2 \\
\hline Confidentiality of the data is low and data might get hacked & 2 & 4 & 1 & 7 & 25 \\
\hline Lack of trust in internet based services & 0 & 4 & 4 & 13 & 18 \\
\hline future with cloud accounting is not so visible & 1 & 8 & 6 & 10 & 14 \\
\hline
\end{tabular}

Source: Survey data

*Special note: $\mathrm{SD}=$ Strongly disagree, $\mathrm{D}=$ Disagree, $\mathrm{N}=$ Neutral, $\mathrm{A}=$ Agree and $\mathrm{SA}=$ Strongly agree 
According to the table $\mathrm{V}$, not popular among peer groups, lower confidentiality of data and lack of trust in internet based services has shown the higher frequencies. Hence those can be considered as the main reasons for the non adoption of cloud accounting among the accounting practitioners.

\section{G) Analysis of future preferences}

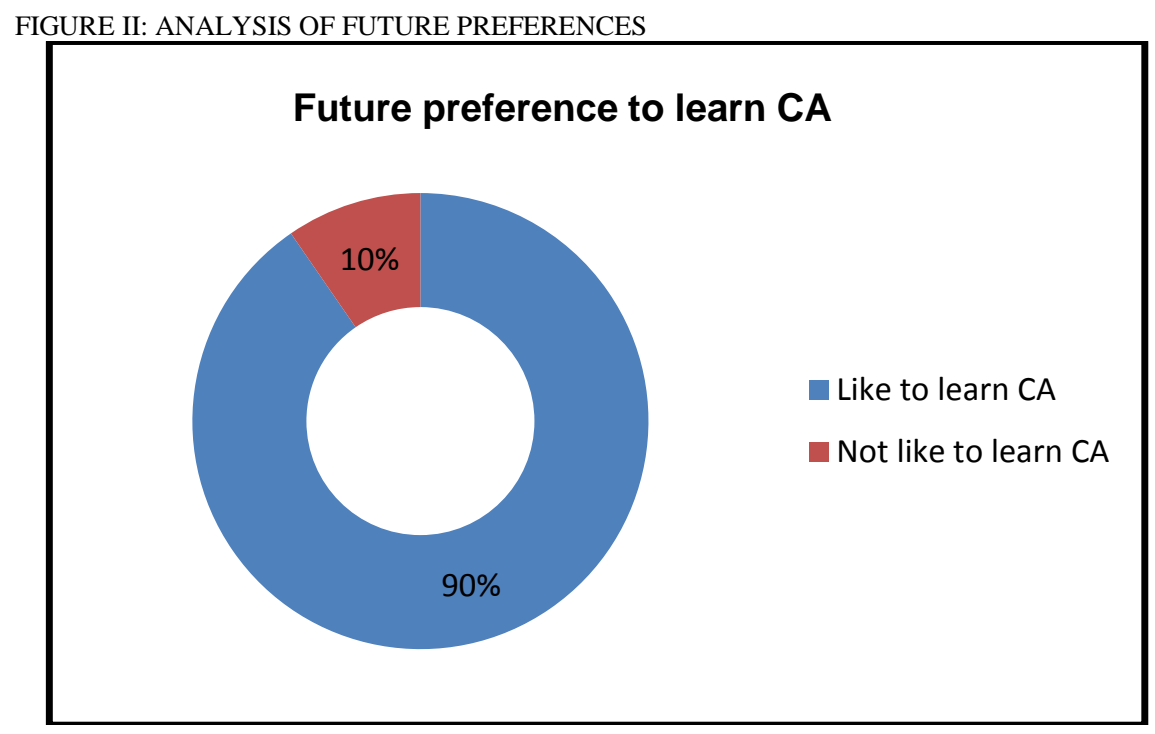

Source: Survey data

As per the Figure II, out of 52 respondents who were not aware about cloud accounting, $90 \%$ of them has shown the willingness to learn cloud accounting while $10 \%$ has not shown the interest.

\section{VI.CONCLUSION}

Though cloud accounting brings out lots of benefits to the organizations, many accounting practitioners seem to be not aware and adopting cloud accounting in their daily practice. In this study, researcher tried to find out the level of awareness, reasons for adoption and non adoption of cloud accounting and the future willingness of accounting practitioners to learn cloud accounting.

The analysis of the survey data has highlighted unlimited and easy geographical access, unlimited data storage, processing capacity and automatic backup, Standardized interfaces for the preparation of accounting reports and Facilitates generation of accounting reports whenever needed as the major reasons for the adoption of cloud accounting. Not popular among peer groups, lower confidentiality of data and lack of trust in internet based services are highlighted as the main reasons for the non adoption of the cloud accounting. As well the findings of the study suggest that respondents not aware about cloud accounting are also like to learn this newly emerging technology.

Based on the existing literature, the researcher has developed the foundation for this study and further researchers has the opportunity to figure out more reasons in this particular context. The findings of this study will be helpful to accounting practitioners, academics, policy makers and the cloud accounting developers in their future developments

\section{V.REFERENCES}

[1]Abdullah, A (2016), A Knowledge Management Based Cloud Computing Adoption (Doctoral dissertation), Staffordshire University.

[2] Ajzen, I., \& Fishbein, M (1980), Understanding attitudes and predicting social behavior, Englewood Cliffs, N.J: Prentice-Hall.

[3]Bosoteanu, MC 2016, 'Cloud accounting in Romania, a literature review', University of Craiova, Romania.

[4]Dimitriu, O \& Matei, M (2015), Cloud Accounting: A New Business Model in a Challenging Context, Procedia Economics and Finance.

[5]Ebenezer, \& Antwi, O. (2014), Accounting in the cloud: how could computing can transform businesses: The Ghanaian perspective, Paper presented at International Conference on Global Business, Economics, Finance and Social Sciences, Chennai.

[6]Honea, S 2021, Best cloud accounting software, Best Accounting software.

[7]Mell, P. and Grance, T (2011), The NIST Definition of Cloud Computing, National Institute of Standards and Technology Special Publication, 53, PP 1-7.

[8]Mihalache, D 2011, Ovidius University Annals, Economic Sciences Series, 2011, vol. XI, issue 2, PP 782-787

\section{AUTHORS}

S.H.M.L Walakumbura, Bsc(Sp) in Financial Management, Sabaragamuwa University of Sri Lanka 